\title{
Changing Incomes and Food Prices: The Implications for Rural and Urban Food Security in Sri Lanka
}

\author{
Shyama Ratnasiri ${ }^{\dagger 1}$, Jayatilleke S. Bandara ${ }^{2}$ and \\ Pradeepa Korale-Gedara ${ }^{3}$
}

\begin{abstract}
Although rising food prices have hit hard on a large number of households in many developing countries, the vulnerability in terms of food security varies across different household sectors within a country. In this study we have developed a simple analytical model and used it to examine the food security vulnerability across different households to a shock in food prices by using three commonly-known household sectors (urban, rural, estate)in Sri Lanka. In particular, we have estimated the combined impact of income and price rises on food security of these sectors. Our empirical results suggest that the overall food security in all three household groups (measured in terms of real food consumption above the poverty line food consumption) has been marginally decreasing over time in Sri Lanka. Furthermore, the negative effect of rising food prices has been partially offset by the positive income effect in all three household sectors. The results also suggest that the urban sector is highly vulnerable to a food price shock than the other two sectors. The least vulnerable group is the rural sector, whilst the estate sector lies in the middle.
\end{abstract}

\section{Introduction}

In recent years, food security has been a major concern amongst policy analysts, policy makers in both developed and developing countries and researchers at global institutions such as the United Nations (UN) and the World Bank. Scholars have still not been able to arrive at an acceptable measure of food security; however it is well accepted that aggregated measures of food security at national level do not reflect the disparities across sub groups or regions (Staaz et al., 1990; Maxwell 1995; Anderson and Cook 1999; Barrett 2010). Furthermore, the experience of the 2008 world food price crisis suggests that households in different sectors in an economy will be exposed to a food crisis in terms of vulnerability to food insecurity in varying

${ }^{1}$ Lecturer, ${ }^{2}$ Associate Professor and ${ }^{3} \mathrm{PhD}$ candidate Department of Accounting, Finance and Economics, Griffith University, Gold Coast, Australia.

${ }^{\dagger}$ Corresponding author, email: s.ratnasiri@griffith.edu.au 
degrees. Studies that analyse the impacts of food security at sub national levels, such as rural and urban levels or other regional levels suggest that the implications of changing economic variables are, in fact, different across those sub groupings. For example, Garrett and Ruel (1999) found that the food security, as well as its determinants, was different across rural and urban areas in Mozambique. Furthermore, a study that analysed the regional price heterogeneity in Ethiopia suggested that location does matter for food security (Ulimwengu et al., 2009). In a comprehensive review which dealt with a large number of countries, Cohen and Garrett (2010) argued that urban low income earners were the most vulnerable group in terms of food security at incidents of food price hikes. ${ }^{1}$ Further, there have been arguments on short term and long term implications of food price increases too (Dorward, 2012). These findings illustrate that it is important to analyse the implications of price and income changes at sub national level. Therefore, the credibility of an aggregated analysis on the effects of rising food prices is highly questionable. This has led to an increase in demand for a disaggregated analysis of food price rises across different household sectors in economies in order to evaluate the impact and policy responses to food crises in the developing world.

In this study, therefore, we aim to explore the impacts of changing incomes and food prices on food security of the households residing in different household sectors by developing a simple analytical model and testing it using Sri Lankan data in order to derive policy implications. The contribution of our study to existing literature is twofold. First, the paper offers a novel and a simple analytical model to measure the food security at regional levels. This model essentially develops an empirically quantifiable measure for food security of consumers. To our knowledge, we are not aware of a similar study although there exists a large number of empirical studies that measure the impact of the food price crisis on rural and urban populations (Kennedy and Peters 1992; Tschirley et al., 1996; Garrett and Ruel 1999; Iram and Butt 2000). Secondly, food security measures have not explicitly been empirically tested at regional levels for most of the South Asian countries, in particular, in the context of Sri Lanka and we have attempted to fill this gap by undertaking the current study.

The rest of the paper is organised as follows. The next section provides a background of Sri Lanka focusing on incomes across different household sectors and food prices. Thereafter we develop the analytical framework to be used in the study. This is followed by a section on data, the

\footnotetext{
${ }^{1}$ Several other studies have presented similar outcomes, see for example, Aksoy and Isik-dikmelik (2010), Zezza and Tasciotti (2010).
} 
empirical estimation procedure and the results. Finally, the concluding remarks are presented.

\section{Sri Lanka as a Case Study}

Sri Lanka is an island nation with more than 20 million people who show notable differences across household sectors. It also experienced a dramatic rise in food prices during the global food crisis in 2008 and many households in Sri Lanka are known to be vulnerable to food insecurity. The country is also focusing on the elimination of poverty and the strengthening of food security situation, particularly after the end of three decade long war in 2009. Therefore, Sri Lanka is an excellent case for this study. In the island, $83 \%$ of the total population still live in rural areas, of which $5 \%$, referred to as the estate sector working and residing at plantation estates that include tea, rubber and coconut. . The remaining 17\% of the population of Sri Lanka live in urban areas (Department of Census and Statistics of Sri Lanka, 2013). In this study, therefore, the location of households is distinguished under the three sectors following the common and long-traditional practice in policy analysis: urban, rural and estate. While the urban sector consists of all areas governed by municipal and urban councils, the estate sector consists of plantation estates with tree crops, namely; tea, rubber and coconut, spanning over more than 20 acres and having no less than ten residential labourers. The rest of the country is categorised as the rural sector. Households in these three sectors significantly vary from each other in terms of socioeconomic characteristics such as income levels, education and health.

In Sri Lanka, the average per capita income, in real terms, has almost doubled from 2002 to 2012, even with negative effects of natural disasters such as the 2004 tsunami and one of Asia's longest civil wars that ended in 2009. This reflects that on average the country performs better than most of the South Asian countries (World Bank, 2013). Due to this significant economic growth in recent years, it has been promoted to the middle income country category, in 2010, by the International Monitory Fund (IMF). The sectoral incomes have also risen but at different rates. This is illustrated in Figure $1 .^{2}$ The highest growth in mean income is recorded in the estate sector followed by the rural and urban sectors. The rapid growth in the estate sector is due to the fact that estate workers are now tending to work in some off estate occupations while still living in the estates. ${ }^{3}$ The lowest income growth rate is recorded in the urban sector.

\footnotetext{
${ }^{2}$ We considered year 2000 as the base year for the variables presented in this figure. i.e. year $2000=100$.

${ }^{3}$ There had been a major wage rise for estate workers in early 2010 (World Bank, 2013).
} 
On the other hand, food prices in Sri Lanka have also increased in recent years; for instance, by 2013, food prices have almost doubled from its $2006 / 2007$ level, while on average, all prices have increased by $75 \%$ from the same base year level. This is also illustrated in Figure 1. As evident from the figure, food inflation is much higher than non-food inflation in recent years. Furthermore, the food price inflation is also different at the regional level. For instance, the urban food inflation can be higher compared to rural, as rural households who are more likely to depend on own local produce.

Figure 1: $\quad$ Price and income changes in Sri Lanka (2003-2011) (Base year, 2002=100)

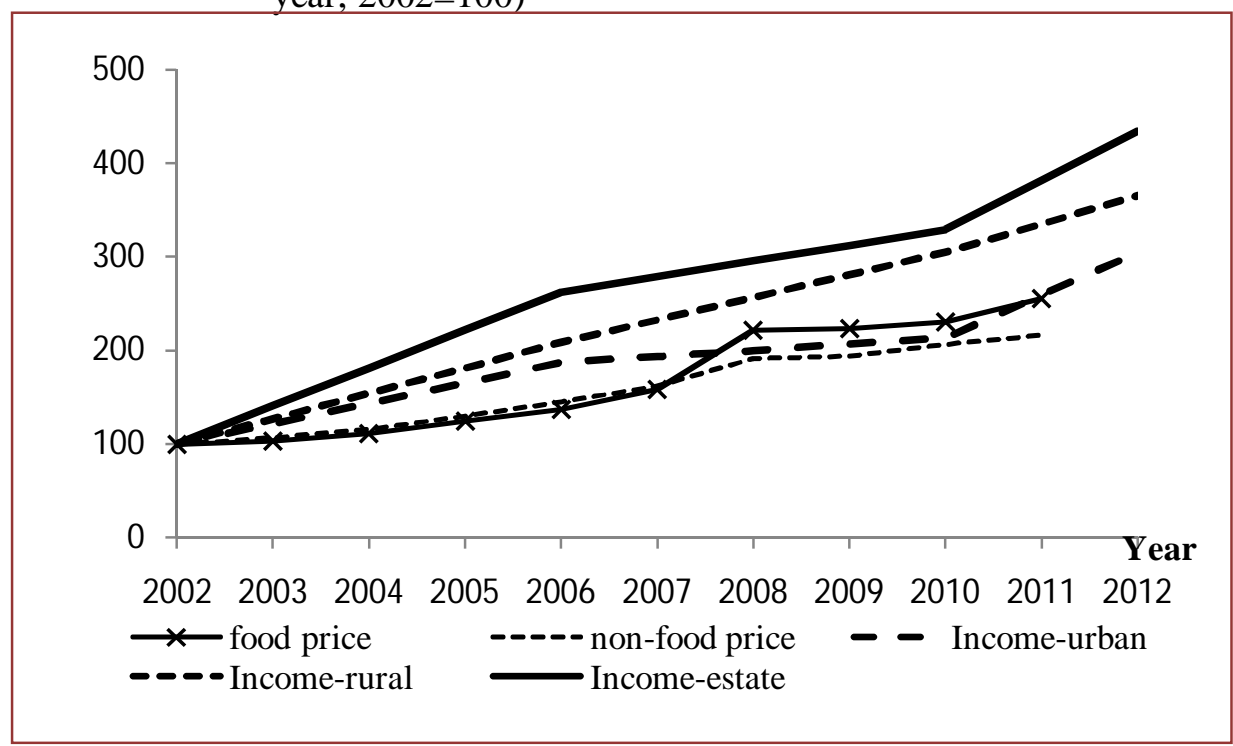

Moreover, it is evident from Figure1 that the income growth and food inflation are fairly uneven across the three sectors. For example, during the period 2002 to 2010, the estate income growth was well above the food price inflation. In contrast, the urban sector growth was fairly marginal until 2008 and thereafter the food inflation rate surpassed the urban income growth rates. ${ }^{4}$ The combined impact of these changes on the ultimate consumer can then obviously have mixed impacts at the regional level, essentially in terms of consumption and food security. This combined impact can also be either severe or mild depending on the other socioeconomic factors of these sectors. As noted above, there is reasonable socioeconomic heterogeneity across these three sectors, which will be discussed in detail next. In this study, we analysed

\footnotetext{
${ }^{4}$ It should be noted that, at this time when had been a huge food price rise in the global level and the impacts of this crisis had also been imparted to Sri Lanka (World Bank, 2010).
} 
the changes in food security resulting from increases in incomes and food inflation across the three sectors.

We now discuss the socio economic and demographic differences across the three sectors in Sri Lanka to provide a comprehensive picture, which is also summarized in Table 1. The most significant difference across the sectors relates to income and its distribution. These variables are changing remarkably; for example, in a month an average household living in an urban area earns more than double of what is earned by an average estate household. An average rural household earns about three fourths of an urban households' income, little above an estate worker. There is a huge disparity in terms of the distribution of this income too. Even though urban incomes are higher, the distribution of income in urban areas is worse compared to estate and rural sectors. On the other hand, estate households work in the estate sector with a formal wage; thus income inequality is the lowest here amongst the three sectors.

In contrast, the estate sector has the highest poverty head count ratio consistent with the estate workers' earnings that are reasonably lower than their rural and urban counterparts. The households living in rural areas depend predominantly on agricultural earnings and also have some off-farm casual incomes receiving a total income higher than that of estate workers. The poverty ratio in urban areas is relatively lower than estate workers. The urban sector records the lowest rate of poverty due to more job opportunities in the urban areas.

Table 1: $\quad$ Summary of rural, urban and estate sector differences in Sri Lanka

\begin{tabular}{|c|c|c|c|c|}
\hline Characteristics & Urban & Rural & Estate & Sri Lanka \\
\hline $\begin{array}{l}\text { Monthly per capita income (Rs.) } \\
\text { (2012) }\end{array}$ & 15,892 & 10,546 & 7,594 & 11,848 \\
\hline $\begin{array}{l}\text { Income inequality (Gini } \\
\text { coefficient) (2012) }\end{array}$ & 0.51 & 0.47 & 0.39 & 0.48 \\
\hline $\begin{array}{l}\text { Poverty (poverty head count ratio } \\
\text { as a \%) (2010) }\end{array}$ & 5.3 & 9.4 & 11.4 & 8.9 \\
\hline $\begin{array}{l}\text { Number of poor persons by sector } \\
\text { (\% of total poor) }\end{array}$ & 8.8 & 84.7 & 6.5 & 100 \\
\hline $\begin{array}{l}\text { Share of food expenditure (\% of } \\
\text { total expenditure) (2012) }\end{array}$ & 0.31 & 0.39 & 0.50 & 0.38 \\
\hline
\end{tabular}

Source: Department of Census and Statistics of Sri Lanka (2013)

Another difference across the three sectors relates to the food consumption patterns and the spending patterns on food. As briefly noted above, agricultural producers living in rural areas have greater access local produce while urban and estate residents purchase most of their food from the 
market (as no data or reference is provided). The expenditure share on food in urban areas is lowest followed by the rural and estate sector. Resembling the well-known Engle's law, low income estate workers spend most of their income on food. In fact their spending on food out of their income was around $60 \%$ in 2002 , showing only a marginal decline over the last several years. In contrast, an average urban household was spending about $30-35 \%$ of its income on food while a rural counterpart spends about $40-45 \%$. It is interesting to note that during the period 2002 to 2012 the nominal food expenditure had significantly increased in all the three sectors, For example, during the period 2002 to 2006 average food expenditure had risen by $45 \%$, $55 \%$ and $63 \%$ respectively in urban, rural and estate sectors (Source??). This is obviously due to the food price inflation recorded in the recent past.

Furthermore, the composition of the diet has been changing over time. Typically, with increases in incomes and urbanization, diets diversify and starch based staple foods are partly replaced by relatively more expensive sources of food items such as animal and dairy products (Pingali, 2007). Rice has been the staple food item and the major source of dietary energy for almost all Sri Lankans. However, recent records suggest that rice is becoming less important in the diet, particularly, in the middle and upper income urban communities (World Bank, 2010). For estate and rural consumers, who are placed towards the bottom end of the income distribution, an increment in income still translates into a purchase of more staple foods mainly to satisfy their energy needs. Furthermore, the religion, ethnic composition and associated food habits also affect the dietary composition. For example, estate communities more often consume wheat based vegetarian diets, whereas rural people tend to eat rice based vegetarian foods for all three meals. Overall, the diet diversity is quite high only in urban areas, due to availability and accessibility.

\section{Analytical Framework}

In this paper the implications of increasing real incomes and food prices on food security is analysed using the food consumption behaviour of consumers. We use a simple analytical model, which is an extended version of the model presented in Korale-Gedara et al. (2012). To begin with, we pick an average consumer ' $i$ ' from the sector ' $j$ ', (where $j=1 . . J$ and $J=3$ ). ${ }^{5}$ Utility derived from the consumption of several goods can be characterised by a Stone-Geary utility function which is commonly used in linear expenditure system analysis. In our study, we use the following Stone-Geary utility function.

\footnotetext{
${ }^{5}$ We drop the sector ' $j$ ' for ease of reference in the rest of the paper.
} 


$$
U_{i t}=\sum_{k=1}^{K} \alpha_{k} \ln \left(C_{i t}^{k}-\bar{c}_{i t}^{k}\right) 0<\alpha<1,\left(C_{i t}^{k}-\bar{c}_{i t}^{k}\right)>0
$$

where $U_{i t}$ denotes the utility of our average consumer ' $i$ ' at time $t, K$ is the total number of goods, where $k=1 \ldots K$. The notations $C_{i t}^{k}$ and $\bar{c}_{i t}^{k}$ represent the consumption of good $k$ at time $t$ and its subsistence level of consumption at the same time respectively. The parameters $\alpha_{k}$ denote the preference for each good $k$. We consider a consumer who receives utility $U_{i t}$ from the consumption of only two goods $(K=2)$; and $k=1$ denotes food consumption $\left(C_{i t}^{f}\right)$ and $k=2$ denotes non-food consumption $\left(C_{i t}^{n f}\right)$ at time t. This average consumer maximizes his/her utility by consuming the subsistence level of food $\left(\bar{c}_{i t}^{f}\right)$ and non-food( $\bar{c}_{i t}^{n f}$ ) first and the remaining income is used to purchase what is referred to as the elastic component of the consumption of the two goods depending on the preference parameters $\alpha_{k}$. Let the price of food be $P_{t}^{f}$ and non-food be $P_{t}^{n f}$ the consumer maximizes utility subject to $I_{t}=\sum_{k=1}^{K} P_{t}^{k} C_{t}^{k}$. Here $I_{t}$ is the consumer's income, $P_{t}^{k}$ is price of $k^{t h}$ good. After solving the simple optimization problem, demand for food can be derived and it is given by the following equation.

$$
C_{i t}^{f}=\bar{c}_{i t}^{f}+\frac{\alpha_{f}}{P_{t}^{f}}\left(I_{t}-\sum_{k=1}^{K} P_{t}^{k} \bar{c}_{i t}^{k}\right)
$$

A reference point can be selected in order to calculate the change in consumption. We chose the national poverty line as our reference point and the details of this will be presented later. We can then write the food demand of a representative consumer on the poverty line with the use of equation (3) too, however we use superscript asterisk to denote this reference consumer. The difference in consumption $\Delta C_{i t}^{f}$ between an average consumer at the $j^{\text {th }}$ sector and the reference consumer (who is on the poverty line) can then be calculated by taking $\Delta C_{i t}^{f}=C_{i t}^{f}-C_{t}^{f^{*}}$, where, $C_{t}^{f^{*}}$ is the food 
consumption of the reference consumer. ${ }^{6} \mathrm{By}$ substituting the equations and simplifying them, we can formulate the following expression to calculate the consumption change $\left(\Delta C_{i t}^{f}\right)$.

$$
\Delta C_{i t}^{f}=\left[\frac{\alpha_{f} I_{t}}{P_{t}^{f}}-\frac{\alpha_{f}^{*} I_{t}^{*}}{P_{t}^{*}}\right]+\left[\left(\alpha_{f}^{*} \bar{c}_{t}^{n f^{*}} \frac{P_{t}^{n f^{*}}}{P_{t}^{f^{*}}}\right)-\left(\alpha_{f} \bar{c}_{i t}^{n f} \frac{P_{t}^{n f}}{P_{t}^{f}}\right)\right]
$$

Next, we simplify the above Equation with the use of very plausible assumptions. We assume that the reference consumer consumes only one food basket and lies exactly on the poverty line. ${ }^{7}$ Due to this assumption, the reference consumer's consumption in the above equation is equal to one food basket (i.e. $\left.\frac{\alpha_{f}^{*} I_{t}^{*}}{P_{t}^{*}}=1\right)$.This indicates that the reference consumer (defined as the poverty line consumer) pays a price that is exactly equal to his total food expenditure to buy a single basket of food. Owing to this assumption, the calculated $\Delta C_{i t}^{f}$ value then represents how many more similar baskets an average consumer consumes than the reference consumer ${ }^{8}$.Secondly, we assumed that the subsistence level of non-food consumption is the same for both the average consumer and the reference consumer and this has been normalized to one basket of non-foods too (i.e. $\bar{c}_{t}^{n f}=\bar{c}_{t}^{n f^{*}}=1$ ). Therefore, Equation 4 can be simplified as

$$
\Delta C_{i t}^{f}=\left[\frac{\alpha_{f} I_{t}}{P_{t}^{f}}-1\right]+\left[\left(\alpha_{f}^{*} \frac{P_{t}^{n f^{*}}}{P_{t}^{f^{*}}}\right)-\left(\alpha_{f} \frac{P_{t}^{n f}}{P_{t}^{f}}\right)\right]
$$

\footnotetext{
${ }^{6}$ Recall we have dropped the " $j$ ” subscript.

${ }^{7}$ Our assumption is plausible as this is exactly how the poverty line is defined in Sri Lanka.

${ }^{8}$ Furthermore, $\frac{P_{t}^{*}}{I_{t}^{*}}=\alpha_{f}^{*}$ because of this assumption. Therefore, a change in the food consumption share $\left(\alpha_{f}^{*}\right)$
} 
In the above equation, the first term $\left(\frac{\alpha_{f} I_{t}}{P_{t}^{f}}\right)$ is the total food expenditure $\left(\alpha_{f} I_{t}\right)$ of the average consumer divided by the food price ( $\left.P_{t}^{f}\right)$.Since we are referring to an identical basket of foods available at different prices, the price effective to an average consumer $\left(P_{t}^{f}\right)$ is different from that of a reference consumer. This average price variable is obtained by converting the price of one food basket at the reference level into the nominal price affecting the average consumer using a relevant price index. ${ }^{9}$

The value of $\left(\Delta C_{i t}^{f}\right)$ represents the additional consumption in real terms that the mean consumer in $j^{\text {th }}$ sector consumes on top of the real food consumption by the reference consumer. We consider this as an indirect measure of food security as this provides an indication - by how much a selected consumer is well off in terms of food, than a consumer at the poverty line who is just meeting his food needs. The details of the data we used to estimate the $\Delta C_{i t}^{f}$ and the estimation steps are presented in the next section.

\section{Empirical Results}

In this section, we present the data used for the empirical testing of the model, in the previous section, and its results. First, we need to choose a reference consumer for our analysis. As mentioned above, we chose the consumer at poverty line as our benchmark. Although there are a number of poverty measures available for Sri Lanka, we choose the official poverty line published by the Department of Census and Statistics of Sri Lanka for 2002. This choice is not only due to its widespread use, but also due its compatibility with our model's reference point. The official poverty line of Sri Lanka is defined as the welfare level at which the average adult fulfils his/her daily energy requirement. In particular, it is the per capita expenditure that a person makes to be able to meet the defined nutritional level of 2030 calories per day in 2002. This consists of both food and non-food expenditure. In 2002 the poverty line was Rs. 1,423, of which Rs. 973 consisted of spending on food. Thus we used these two baskets of goods as our reference points. Essentially we assumed that a person at the poverty line consumes two baskets; the food basket valued at Rs. 973 and the non-food basket valued at

\footnotetext{
${ }^{9}$ This can be the spatial price index for different regions or in the case when the consumer is in time $(t+1)$, one can inflate this using the food inflation rate.
} 
Rs. 450. In our model, this is the reference consumer's price of food $\left(P_{t}^{f^{*}}\right)$ and non-food price $\left(P_{t}^{n f^{*}}\right)$. As mentioned above, this assumption allows us to work out how many more similar baskets are consumed by other consumers.

Next, we constructed the average prices of food and non-food with effect to rural, urban and estate sector consumers. We used a spatial price index applicable to the three sectors. ${ }^{10}$ Using these sectoral price indices we converted the price of the reference food basket into prices effective to rural urban and estate sector consumers. This meant that consumers of the three sectors were paying different prices to purchase the same food basket consumed by a consumer at the poverty line. This is in fact, the average food price $\left(P_{t}^{f}\right)$ and average non-food price $\left(P_{t}^{n f}\right)$ paid by the mean consumer in each sector in our model.

Now, we describe data for our average consumer's food expenditure which is given as $\left(\alpha_{f} I_{t}\right)$ in Equation 5. We obtained this data from the Department of Census and Statistics of Sri Lanka. This is calculated by dividing the total household expenditure on food by the household size. Next we calculated the change $\left(\Delta C_{t}^{f}\right)$ in the real food consumption of the average consumer using Equation 5.

We calculated the same figure $\Delta C_{t}^{f}$ for two other years i.e. 2006 and 2010. For this, the corresponding inflation rates were used to deflate sectoral food and non-food prices. Typically, the official poverty line is updated each year by using the average increases in the Colombo Consumer Price Index (CCPI), however in our study we look at the food and non-food inflation separately and inflated the poverty line accordingly to 2006 and 2010. Our calculated poverty lines are 2132 and 3385 for these two years. This exercise enables us to analyse the food and non-food inflation faced by the economy separately.

\footnotetext{
${ }^{10}$ Spatial price index for Sri Lanka is calculated for different districts to convert the national poverty line in to district levels. In our study, we use the districts with more than 50\% rural population as rural districts and calculate the rural price index. Following a similar argument, districts with more than 50\% estate population are classified into estate sector and calculated the estate price index. We use the Colombo consumer price index (CCPI) for urban price index.
} 
Table 2: $\quad$ Per capita consumption of food above the consumption of a consumer at poverty line (Consumption at the poverty line $=1)$.

\begin{tabular}{cccc}
\hline Year & \multicolumn{3}{c}{ Incremental food consumption $\left(\Delta C_{t}^{f}\right)$} \\
\hline \multirow{2}{*}{2002} & Urban & Rural & Estate \\
2006 & 0.96 & 0.54 & 0.38 \\
2010 & 0.82 & 0.54 & 0.28 \\
& 0.60 & 0.44 & 0.30 \\
\hline
\end{tabular}

The empirical results are presented in Table 2. The estimated values measure the per capita food consumption of an average consumer than that of the poverty line consumer. Recall that the bench mark (poverty line) consumption is set equal to one.

The empirical results of our simple analytical model provide a number of very strong and interesting messages. Firstly, as evident from Table 2, the computed real food consumption figures for average consumers in all three sectors are above the poverty line consumer. This implies, obviously, that an average consumer from each sector is well off in terms of her/his food consumption compared to a poverty line consumer. Secondly, Table 2 further illustrates that there is a significant difference between rural urban and estate sector consumption. For example, in 2002, an average urban consumer consumed food almost twice as what was consumed by the poverty line consumer. In the same year, an average rural consumer consumed 54\% more than what was consumed by the poverty line consumer while this was $38 \%$ more in the estate sector. This is not surprising compared to the income, its distribution and poverty incidents across these three sectors; urban consumers spends more on food than rural and estate consumers.

Thirdly, as can be observed from our data, the food share of income has slowly declined or remained stable in Sri Lanka during the study period. This implies that real incomes of consumers have increased marginally because food prices have increased significantly during the same period. For this reason our results suggest that the food security has not remarkably improved in any of the sectors over time in the island. In fact, the increasing incomes have not been able to improve the food security, and the deleterious effects of food price rises had only partially been offset by the effect of increase in income during the study period, in particular during the period $2002-2006$. 
Finally and most importantly, the results suggest that the urban sector is more vulnerable in terms of food security compared to rural and estate sectors. Recall that the income level in the urban sector on average was not rising in par with the food inflation after 2008. In fact, the food inflation rate was higher than the urban income growth. This factor essentially aggravates the food security level of the urban consumers over time. Our results demonstrate that it is more likely that the negative effects of food inflation or food price shocks are very destructive to the food security of the marginal income earners in the urban sector. The food security vulnerability of the urban low income earners (often net food buyers) to price hikes has been discussed widely in the related literature, (see for example Ivanic and Martin 2008; Ulimwengu et al., 2009; Ruel et al., 2010). Our results are also consistent with the results of previous studies. On the other hand, the rural sector, in fact, is more resilient to food price rises. As apparent from the figures presented in Table 2, rural real food consumption was 54\% in both 2002 and 2006 (no change during the period), and it has decreased only by $10 \%$ in 2010. The estate sector recorded a $10 \%$ decrease in 2006; however, this sector was able to catch up, in part, in 2012. The recorded growth in real income in the estate sector has contributed to this outcome.

\section{Concluding Remarks}

As identified in recent literature, households in many developing countries are exposed in varying degrees to changes in income and food prices. Identifying the differential impacts of these changes on different household groups or sectors is crucial to ensure that food security and poverty reduction policies are well targeted. In this paper we have made an attempt to analyse the impacts of economic growth and food price inflation on food security of three well-established household groups in Sri Lanka. A simple analytical model was developed in the first part of this paper. The analytical model was then tested in the second part of this paper with the use of Sri Lankan data. The empirical results provide some important and significant findings in terms of food security.

According to the empirical results presented in the previous section, the overall food security situation (measured in terms of real food consumption above the poverty line food basket) of the three main household groups in Sri Lanka has been decreasing over time. This is a very interesting finding considering the fact that the overall poverty levels in these three sectors have declined over the last ten years or so. The real income growth, although extremely important to ensure food security, has still not been able to produce remarkable improvements in household food security. Yet, it has been offsetting the negative effects of extreme price hikes. Our findings further suggest that there is a significant difference in the way that different 
household groups respond to combined effects of income and price rises. On average, at any given time, the average urban real food consumption is higher than that of rural and estate sectors. However, in the presence of deleterious effects of price increases, the urban sector is significantly vulnerable in terms of food security. This is more likely due to the presence of poor urban population. The least vulnerable sector is the rural sector, and the estate sector lies in the middle.

As noted in the paper, our empirical results are based on a simple analytical model. In order to draw much broader and concrete lessons for policy formulation, further studies are needed in the same direction. In particular, the current study explicitly captures the impact of income and price changes on the average consumer of the each sector, which has not been considered in the previous literature. However, our model does not capture the impact of income and price changes on the poor consumers who are more vulnerable than the average consumer. This is because our model does not recognize consumers at each income level, in particular, quartile or decile level. Therefore, the policy inferences on the poor cohort are quite limited in this study. For future directions of research, therefore, we suggest carrying out a similar study with a more disaggregated level of households; for example, a study at various income deciles within each sector will be able to provide a more targeted policy inference. Future research can also be directed towards the testing of the analytical model presented in this paper by using data from other developing countries. In such studies, the reference consumer needs to be appropriately defined.

\section{References}

Aksoy, M.A., and A.Y.L.I.N. Isik-dikmelik (2010). Are Low Food Prices Pro-Poor? Net Food Buyers and Sellers in Low-Income Countries83.Centre for Economic Policy Research, 113.

Anderson, M.D. and J.T. Cook (1999). Community Food Security: Practice in Need of Theory? Agriculture and Human Values, 16(2): 141-150.

Barrett, C.B. (2010). Measuring Food Insecurity. Science, 327(5967): 825828.

Cohen, M.J. and J.L. Garrett (2010). The Food Price Crisis and Urban Food (in) Security. Environment and Urbanization, 22(2): 467-482.

Department of Census and Statistics Sri Lanka (2013). Household Income and Expenditure Survey 2012/2013: Preliminary Results of First Three 
Monthly Rounds. Department of Census and Statistics Sri Lanka. Sri Lanka.

Dorward, A. (2012). The Short-and Medium-term Impacts of Rises in Staple Food Prices. Food Security, 4(4): 633-645.

Garrett J. and M. Ruel (1999) Are Determinants of Rural and Urban Food Security and Nutritional Status Different? Some insights from Mozambique, World development, 27(11): 1955-1975.

Iram, U. and M.S. Butt (2004). Determinants of Household Food Security: An Empirical Analysis for Pakistan. International Journal of Social Economics, 31(8): 753-766.

Ivanic, M. and W. Martin (2008). Implications of Higher Global Food Prices for Poverty in Low-income countries1, Agricultural Economics, 39: 405-416.

Kennedy, E. and P. Peters (1992). Household Food Security and Child Nutrition: The Interaction of Income and Gender of Household Head. World Development, 20(8): 1077-1085.

Korale-Gedara, P.M., S. Ratnasiri and J. Bandara (2012). Soaring Food Prices and Food Security: Does the Income Effect Matter? Applied Economics Letters, 19(18): 1807-1811.

Maxwell, D.G. (1995). Alternative Food Security Strategy: A Household Analysis of Urban Agriculture in Kampala. World Development, 23(10): 1669-1681.

Pingali, P.L. (2007). Westernization of Asian Diets and the Transformation of Food Systems: Implications for Research and Policy. Food Policy, 32(3): 281-298.

Ruel, M.T., J.L. Garrett, C. Hawkes and M.J. Cohen (2010). The Food, Fuel, and Financial Crises affect the Urban and Rural Poor Disproportionately: A Review of the Evidence. The Journal of Nutrition, 140(1): 170S-176S.

Staatz, J.M., V.C. D'Agostino and S. Sundberg (1990). Measuring Food Security in Africa: Conceptual, Empirical, and Policy Issues. American Journal of Agricultural Economics, 72(5): 1311-1317.

Tschirley, D., C. Donovan and M.T. Weber (1996). Food Aid and Food Markets: Lessons from Mozambique. Food Policy, 21(2): 189-209. 
Ulimwengu, J.M., S. Workneh and Z. Paulos (2009). Impact of Soaring Food Price in Ethiopia: Does Location Matter? IFPRI Discussion Paper, 00846.

World Bank ( 2010). Food Price Increases in South Asia. National Responses and Regional Dimentions. The World Bank. Washington, DC.

World Bank (2013). World Development Indicators. $<$ http://data.worldbank.org/data-catalog/world-developmentindicators>.

Zezza, A., and L. Tasciotti (2010). Urban Agriculture, Poverty, and Food Security: Empirical Evidence from a Sample of Developing Countries. Food Policy, 35(4): 265-273. 